Editors' Note: Commenting on the updated diagnostic criteria for pseudotumor cerebri syndrome (PTCS), De Simone et al. explain why the lumbar puncture (LP) opening pressure (OP) is not sufficient to make the diagnosis of PTCS. Commenting on the same criteria, Dasheiff explains how table 1 in the article may be misleading and should reflect more the association of those conditions cited with PTCS rather than causality. Friedman et al., authors of the criteria, respond.

-Chafic Karam, MD, and Robert C. Griggs, MD

\section{REVISED DIAGNOSTIC CRITERIA FOR THE PSEUDOTUMOR CEREBRI SYNDROME IN ADULTS AND CHILDREN}

Roberto De Simone, Angelo Ranieri, Silvana Montella, Naples: While we appreciate the idiopathic intracranial hypertension (IIH) criteria update by Friedman et al., ${ }^{1}$ OP alone does not negate the diagnosis of $\mathrm{IIH} /$ IIH without papilledema (IIHWOP). If an OP above $250 \mathrm{~mm} \mathrm{H} \mathrm{H}_{2} \mathrm{O}$ is required, many cases will be missed.

Intracranial pressure (ICP) monitoring ${ }^{2-5}$ demonstrated that ICP shows large diurnal fluctuations in IIH/IIHWOP patients, ranging from normal to definitely pathologic values. Many patients with papilledema fulfilling Friedman criteria A-D might be classified as "definite" or "probable" depending on the timing of their unstable ICP estimation. Similarly, in chronic headache patients without papilledema presenting with abducens palsy (uncommon also in cases with papilledema) or with a combination of 3 out of 4 suggestive radiologic findings, the diagnosis of IIHWOP will vary from "definite" to "not suggested" largely depending on LP timing.

Considering ICP fluctuations and impracticability of routine ICP monitoring, OP, paradoxically, should never constitute the only reason to refute IIH/IIHWOP diagnosis. In a large chronic primary headache series, ${ }^{5}$ a continuous or intermittent ICP greater than $200 \mathrm{~mm}$ $\mathrm{H}_{2} \mathrm{O}$ was associated with sinus stenosis. We recommend keeping the $200 \mathrm{~mm} \mathrm{H}_{2} \mathrm{O}$ cutoff value at least until the role of venous stenosis in IIH mechanisms is clarified.

Author Response: Deborah I. Friedman, Dallas; Grant T. Liu, Philadelphia; Kathleen B. Digre, Salt Lake City: We agree with De Simone et al. that LP OP alone is not suitable for making a diagnosis of IIH with or without papilledema and this was one of the main reasons that the new criteria are more stringent. The new criteria require papilledema or a sixth nerve palsy for a definite diagnosis of PTCS and more than one neuroimage result for patients without papilledema. The old cutoff value of $200 \mathrm{~mm}$ of CSF was arbitrary and based on a misinterpretation of a previous study that showed values of $250 \mathrm{~mm}$ CSF or greater were diagnostic, those less than $200 \mathrm{~mm}$ CSF were normal, and values between 200 and 249 mm CSF were nondiagnostic. ${ }^{6}$ Our cutoff values for OP are based on this previous study in adults with an unquestionable diagnosis of PTCS and are consistent with the previous criteria specifying an OP of $250 \mathrm{~mm}$ CSF in adults. ${ }^{7}$ The values for children are based on a reference range to determine normal OP. Those values were confirmed in a second study showing that most children with papilledema had OP above $280 \mathrm{~mm} \mathrm{CSF} .{ }^{8,9}$ Diplopia is more common in patients with papilledema than without papilledema but is sometimes the initial presentation of PTCS before papilledema develops. As De Simone et al. correctly pointed out, the presence of transverse venous sinus stenosis as an isolated neuroradiologic finding does not appear to distinguish true IIH/PTCS from chronic primary headache; thus 2 other accompanying imaging findings must be present to meet the imaging criteria.

(C) 2014 American Academy of Neurology

1. Friedman DI, Liu GT, Digre KB. Revised diagnostic criteria for the pseudotumor cerebri syndrome in adults and children. Neurology 2013;81:1159-1165.

2. Johnston I, Paterson A. Benign intracranial hypertension: I: diagnosis and prognosis. Brain 1974;97:289-300.

3. Spence JD, Amacher AL, Willis NR. Benign intracranial hypertension without papilledema: role of 24-hour cerebrospinal fluid pressure monitoring in diagnosis and management. Neurosurgery 1980;7:326-336.

4. Torbey MT, Geocadin RG, Razumovsky AY, Rigamonti D, Williams MA. Utility of CSF pressure monitoring to identify idiopathic intracranial hypertension without papilledema in patients with chronic daily headache. Cephalalgia 2004;24:495-502.

5. Bono F, Salvino D, Tallarico T, et al. Abnormal pressure waves in headache sufferers with bilateral transverse sinus stenosis. Cephalalgia 2010;30:1419-1425.

6. Corbett JJ, Mehta MP. Cerebrospinal fluid pressure in normal obese subjects and patients with pseudotumor cerebri. Neurology 1983;33:1386-1388. 
7. Friedman DI, Jacobson DM. Diagnostic criteria for idiopathic intracranial hypertension. Neurology 2002;59: 1492-1495.

8. Avery RA, Shah SS, Licht DJ, et al. Reference range of cerebrospinal fluid opening pressure in children undergoing diagnostic lumbar puncture. N Engl J Med 2010;363:891-893.

9. Avery RA, Licht DJ, Shah SS, et al. CSF opening pressure in children with optic nerve head edema. Neurology 2011; 76:1658-1661.

\section{DUCKS IN A ROW}

Richard Dasheiff, Dallas: I applaud Friedman et al. ${ }^{1}$ on their attempt to clarify and improve the conceptualization of PTCS. In this process, they inadvertently stumbled over the supporting and ancillary data. Table 1, even with references, is a reflection of inadequate understanding and inappropriate use of associations made between a given disease/syndrome and potential etiologies. For example, many patients have renal failure, anemia, sleep apnea, and Down syndrome, but PTCS is rare, and the cause and effect relationship is unknown in patients who have both. To further impugn the table, sleep apnea is not a disorder of hypercapnia-nor hypoxia—but fractionated sleep causing excessive daytime sleepiness. ${ }^{2}$ If authors wish to convince readers to adopt a new classification system and diagnostic criteria, then all their ducks must be in a row. The article would have been better without table 1 as it needs improvement.

Author Response: Deborah I. Friedman, Dallas; Grant T. Liu, Philadelphia; Kathleen B. Digre, Salt Lake City: The goal of our article was to clarify the diagnostic criteria for PTCS and provide a list of commonly associated secondary conditions. ${ }^{1}$ The associated conditions listed are exactly that-associationsand we did not mean to imply that they were causal. A discussion of etiology and pathogenesis is beyond the scope of our article, yet the list of associations provides no real clues as to the mechanism of developing intracranial hypertension. However, PTCS and IIH are rare disorders. It could be argued, and we often do, that IIH is a disorder affecting obese women of childbearing age. There are many women around the world who fit that description but very few develop IIH. There may be a genetic component that makes some women susceptible and we eagerly await the results of the $\mathrm{IIH}$ trial for more answers.

(C) 2014 American Academy of Neurology

1. Friedman DI, Liu GT, Digre KB. Revised diagnostic criteria for the pseudotumor cerebri syndrome in adults and children. Neurology 2013;81:1159-1165.

2. Dasheiff RM, Finn R. Clinical foundation for efficient treatment of obstructive sleep apnea. J Oral Maxillofac Surg 2009;67:2171-2182.

\section{WriteClick: Rapid Online Correspondence}

The editors encourage comments about recent articles through WriteClick:

Go to www.neurology.org and click on the "WriteClick" tab at the top of the page. Responses will be posted within 72 hours of submission.

Before using WriteClick, remember the following:

- WriteClick is restricted to comments about studies published in Neurology within the last eight weeks

- Read previously posted comments; redundant comments will not be posted

- Your submission must be 200 words or less and have a maximum of five references; reference one must be the article on which you are commenting

- You can include a maximum of five authors (including yourself) 


\section{Neurology}

\section{Revised diagnostic criteria for the pseudotumor cerebri syndrome in adults and children}

Roberto De Simone, Deborah I. Friedman, Angelo Ranieri, et al. Neurology 2014;82;1011-1012

DOI 10.1212/WNL.0000000000000200

\section{This information is current as of March 17, 2014}

\section{Updated Information \&} Services

References

Permissions \& Licensing

Reprints including high resolution figures, can be found at: http://n.neurology.org/content/82/11/1011.full

This article cites 9 articles, 4 of which you can access for free at: http://n.neurology.org/content/82/11/1011.full\#ref-list-1

Information about reproducing this article in parts (figures,tables) or in its entirety can be found online at:

http://www.neurology.org/about/about_the_journal\#permissions

Information about ordering reprints can be found online: http://n.neurology.org/subscribers/advertise

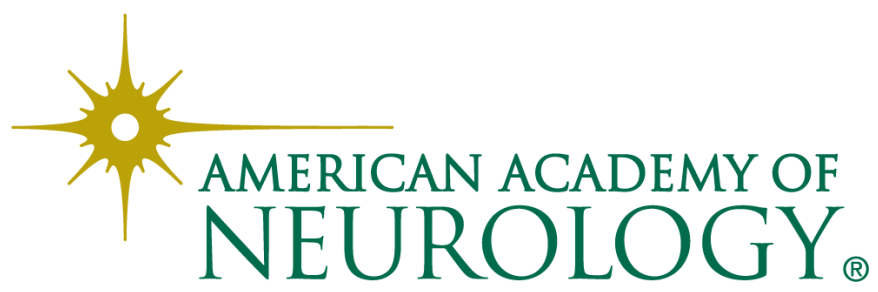

